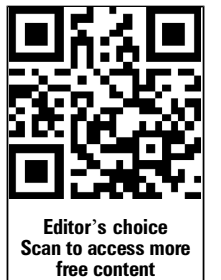

'Department of Medicine, Division of Neurology, University of British Columbia, Vancouver, British Columbia, Canada

${ }^{2}$ Department of Medicine, Division of Neurology and Brain Research Centre, University of British Columbia, Vancouver, BC, Canada ${ }^{3}$ Department of Medicine, Division of Neurology, MS/MRI Research Group, University of British Columbia, Vancouver, British Columbia, Canada ${ }^{4}$ Multiple Sclerosis Research Unit, University of Ottawa, Ottawa, Ontario, Canada

\section{Correspondence to} Dr Helen Tremlett, Faculty of Medicine (Neurology), University of British Columbia, Rm S178, UBC Hospital,

2211 Wesbrook Mall

Vancouver, BC,

Canada V6T 2B5;

helen.tremlett@ubc.ca

Received 11 January 2013 Revised 10 May 2013 Accepted 12 May 2013 Published Online First 6 June 2013
To cite: Menon $S$, Shirani A, Zhao Y, et al. J Neurol Neurosurg Psychiatry 2013;84:1192-1198.

RESEARCH PAPER

\title{
Characterising aggressive multiple sclerosis
}

\author{
Suresh Menon, ${ }^{1}$ Afsaneh Shirani, ${ }^{2}$ Yinshan Zhao, ${ }^{3}$ Joel Oger, ${ }^{2}$ Anthony Traboulsee, \\ Mark S Freedman, ${ }^{4}$ Helen Tremlett $^{2}$
}

\begin{abstract}
Objective To explore the occurrence and characteristics of aggressive multiple sclerosis (AMS) in adult-onset multiple sclerosis (MS) patients.

Methods Prospectively collected data (1980-2009) from British Columbia, Canada, were retrospectively analysed. AMS was defined in three different ways (AMS1, 2 and 3): 'AMS1'—confirmed Expanded Disability Status Scale (EDSS) $\geq 6$ within 5 years of MS onset; 'AMS2' - confirmed EDSS $\geq 6$ by age 40; and 'AMS3' - secondary progressive MS within 3 years of a relapsing-onset course. Three respective 'non-aggressive' MS comparison cohorts were selected. Patients' characteristics were compared between aggressive and non-aggressive cohorts using multivariable logistic
\end{abstract} regression, with findings expressed as adjusted OR (AOR) and $95 \% \mathrm{Cl}$.

Results Application of the three definitions to the source population of 5891 patients resulted in 235/4285 (5.5\%) patients fulfilling criteria for AMS1 $(59.6 \%$ were female; $74.5 \%$ had relapsing-onset MS), 388/2762 (14.0\%) for AMS2 (65.2\% were female; $92.8 \%$ had relapsing-onset MS) and 195/4918 (4.0\%) patients for AMS3 (61.0\% were female). Compared to the respective control cohorts, those with AMS were more likely to be male (AOR=1.5, 95\% Cl 1.1 to 2.0 (AMS1); 1.6, 95\% $\mathrm{Cl} 1.3$ to 2.1 (AMS2); $1.8,95 \% \mathrm{Cl} 1.3$ to 2.4 (AMS3)), older at MS symptom onset (AOR=1.1; $95 \% \mathrm{Cl} 1.1$ to 1.1 (AMS1 and AMS3)) and have primary progressive MS (AOR=2.3, 95\% Cl 1.6 to 3.3 (AMS1); 2.7, 95\% Cl 1.7 to 4.4 (AMS2)).

Conclusions AMS was identified in $4-14 \%$ of patients, depending on the definition used. Although there was a relative preponderance of men and primary progressive MS presenting with AMS, the majority of patients were still women and those with relapsing-onset MS.

\section{INTRODUCTION}

Multiple sclerosis (MS) is a common cause of neurological disability in young adults, ${ }^{1}$ although the actual rate of progression and disability accumulation varies considerably. Rapid progression represents one extreme of the disease, referred to by some as 'aggressive'2-9 or 'malignant ${ }^{\text {'-12 }}$ MS. However, despite this being the most challenging disease course to deal with, there is no consensus or broadly accepted terminology or definition. The most widely used consensus criteria describing the disease phases in MS only provide a broad descriptive definition of 'malignant' MS as a "disease with a rapid progressive course, leading to significant disability in multiple neurologic systems or death in a relatively short time after disease onset". ${ }^{13}$ Consequently, very little is known about the prevalence or incidence of this extreme phenotype, and despite its potentially serious consequences, it is rarely explicitly examined in large populationbased studies.

The absence of a population-based definition also represents an important unmet need with regard to evaluation of possible treatments for aggressive MS (AMS). In today's age of highly active immunosuppressive drug therapy and stem cell transplantation, defining and understanding the epidemiology of AMS is a fundamental, important first step. We have purposely avoided the term 'malignant' MS to avoid confusion with the distinct 'fulminant' Marburg's variant of MS, which is characterised by a severe monophasic illness with little recovery leading to death in a short time. ${ }^{11}$ 14-20

We set out to explore the much needed criteria for AMS and to examine the characteristics of these patients by accessing a large longitudinal populationbased data set in British Columbia, Canada. The main goal was to identify and describe patients with AMS by means of three different, explicit, clearly defined and unambiguous criteria for AMS that could be used by others. Here, we report on the demographic and clinical characteristics of these three groups with AMS. In addition, as a secondary aim we investigated how these three criteria broadly performed in terms of identifying AMS by comparing disease progression between the three groups after the definition of AMS had been reached.

\section{METHODS}

\section{Study design and setting}

Prospectively collected data from the British Columbia MS (BCMS) database were retrospectively analysed. The BCMS database was established in 1980 and is a population-based longitudinal database covering all four MS clinics (Vancouver, Victoria, Kelowna and Prince George) in the province of British Columbia, Canada (until the end of 2004 after which not all four clinics were linked). The database is estimated to capture about $80 \%$ of the MS population in British Columbia. ${ }^{21} 22$ At the first clinic visit, a detailed clinical history, supported by physician referral letter(s), is obtained by the MS-specialised neurologist. Subsequent information, including Expanded Disability Status Scale (EDSS) evaluations, is collected prospectively at each neurologist-patient encounter, typically on an annual basis, although more frequent visits could occur.

\section{Patient selection}

We included patients with adult-onset ( $\geq 18$ years), definite MS (Poser ${ }^{23}$ or McDonald criteria ${ }^{24}$ ), who 
were enrolled in the database from 1980 to 2009. Patients without an EDSS score were excluded. Disease course at onset was classified clinically into either a primary progressive (PP) or relapsing-onset $(\mathrm{RO})$ course. The onset of secondary progressive multiple sclerosis (SPMS) was assigned by the treating neurologist, as in previous studies ${ }^{25-27}$ and concurred with the definition outlined by Lublin and Reingold in 1996, ${ }^{13}$ although these guidelines were not published until after the database was established.

\section{Defining AMS and the control cohorts}

We explored three different definitions for AMS (AMS1, 2 and 3): 'AMS1'-reached confirmed EDSS 6 or greater within 5 years from the onset of MS symptoms; 'AMS2'-reached confirmed EDSS 6 or greater by age 40; and 'AMS3'-reached SPMS within 3 years of a RO course (primary progressive multiple sclerosis (PPMS) patients were excluded). In addition, a combined cohort of patients who satisfied at least one of the EDSS-based criteria for AMS (ie, AMS1 or 2) was also considered. Confirmation of EDSS was achieved when a subsequent EDSS score $\geq 6$, at least 150 days later but within 5 years of the first recorded EDSS $\geq 6$, was recorded. Three comparison cohorts of patients without AMS (C1, 2 and 3) were selected as follows: 'C1' comprised patients known not to have reached EDSS 6 within 5 years from the onset of MS symptoms; ' $C 2$ ' consisted of patients known not to have reached EDSS 6 or greater by age 40 years with the onset of MS symptoms between 18 and 40 years of age; and 'C3' included patients known not to have reached SPMS within 3 years of a RO course. The comparator cohort for the combined cohort of patients who satisfied at least one of the EDSS-based criteria for AMS (AMS1+AMS2) comprised of patients who were known not to have reached an EDSS 6 within 5 years from the onset of MS symptoms or by age 40 years (both criteria had to be fulfilled).

Care was taken when selecting cases and controls to ensure that a potential case could not be included as a control and vice versa. For instance, for the comparator cohorts, the definitions were created to ensure that patients had sufficient time and opportunity to be considered as having AMS before being selected as controls. In addition, patients first seen in the clinic beyond 5 years from symptoms onset with an EDSS $\geq 6$ were not considered eligible for criterion AMS1 (or as a corresponding control, C1) as their EDSS status in the first 5 years was unknown. Similarly patients who were first seen in the clinic after 40 years of age with an EDSS $\geq 6$ were not considered eligible for criterion AMS2 or C2 since the EDSS status by age 40 years was unknown. To prevent potential selection bias, patients exposed to a disease-modifying drug (DMD) were not excluded; instead DMD use was described for the different cohorts.

\section{Statistical analyses}

Characteristics of the aggressive and non-aggressive cohorts were initially compared using the $\chi^{2}$ test for sex and disease course (RO vs PP) and the $t$ test for age at MS onset. Multivariable analysis was performed using forward stepwise logistic regression with onset age, sex and disease course (RO vs $\mathrm{PP}$ ) as covariates (where appropriate) and AMS status (yes, no) as the outcome. Findings were expressed as adjusted OR (AOR) with corresponding 95\% CI.

\section{Sensitivity analysis}

We also performed a sensitivity analysis (primarily aimed at AMS1) to test whether we inadvertently excluded patients who may have had AMS (as defined by AMS1) but came to the clinic late (ie, after the 5 -year window), by extending the time to the first EDSS 6 from 5 to 8 years. The characteristics of this extended cohort were compared with those of a corresponding comparator cohort, that is, those who had not reached EDSS 6 after 8 years of disease duration.

\section{Time to EDSS 8}

In order to ascertain whether the identified AMS patients continued to broadly represent AMS once the criteria were reached, we investigated subsequent disease progression by estimating the time to EDSS 8 from the first EDSS score of $\geq 6$ using KaplanMeier survival curves. The survival times for each of the three AMS cohorts-AMS1, AMS2 and AMS3-were reported. Because of very high rates of right censoring in the comparator cohorts, whom by definition did not contain any patients with AMS, time to EDSS 8 in these cohorts was not investigated.

Statistical analyses were performed using the Predictive Analytics Software (PASW) Statistics V.18.0 (SPSS Inc., Chicago, Illinois, USA).

\section{RESULTS}

Overall, 5891 patients with definite adult-onset MS with at least one recorded EDSS score were extracted from the BCMS database; their characteristics are shown in table 1. In all, 297 patients were excluded from the study because they had no recorded EDSS scores. Those excluded were similar to those included with respect to sex (males $=85 / 297,28.6 \%$ vs 1646 / $5891,27.9 \%, \mathrm{p}=0.78)$. However, excluded patients were older at onset $(35.2 \pm 10.8$ vs $33.4 \pm 9.6$ years, $\mathrm{p}<0.01)$ and more likely to have PPMS $(41 / 297,13.8 \%$ vs $589 / 5891,10.0 \%$, $\mathrm{p}=0.03)$.

From the source population of 5891 patients, those fulfilling criteria for AMS (AMS1, 2 and 3) and the corresponding comparator cohorts (C1, 2 and 3) were selected and are described in table 2. While selecting patients for criterion AMS1 and the comparator cohort $\mathrm{C} 1,810$ patients were not considered as they first came to clinic more than 5 years after the onset of symptoms and already had an EDSS score of 6 or greater. They were similar to the source population in terms of onset age $(33.1 \pm 10.2$ vs $33.4 \pm 9.6$ years, $\mathrm{p}=0.41)$, but were more likely to be male $(258 / 810,31.9 \%$ vs $1646 / 5891,27.9 \%, \mathrm{p}=0.01)$ and have PPMS $(192 / 810,23.7 \%$ vs $589 / 5891,10.0 \%$, $\mathrm{p}<0.01)$. Similarly, while selecting patients for criterion AMS2 and the comparator cohort $\mathrm{C} 2,786$ patients were not

Table 1 Characteristics of the source multiple sclerosis population, British Columbia, Canada

\begin{tabular}{lc}
\hline Characteristic & Value \\
\hline $\begin{array}{l}\text { Total population, number } \\
\text { Sex, number (\%) }\end{array}$ & 5891 \\
$\quad$ Male & $1646(27.9)$ \\
$\quad$ Female & $4245(72.1)$ \\
Disease course, number (\%) & \\
$\quad$ Primary progressive MS & $589(10.0)$ \\
$\quad$ Relapsing-onset MS & $5302(90.0)$ \\
Age at symptom onset, years & \\
$\quad$ Mean $\pm S D$ & $33.4(9.57)$ \\
$\quad$ Range & $18.0-75.2$ \\
\hline MS, multiple sclerosis. &
\end{tabular}


Table 2 Patient characteristics of those fulfilling the different criteria for aggressive multiple sclerosis (AMS 1, 2 and 3) and the non-aggressive comparator cohorts (C1, 2 and 3)

\begin{tabular}{|c|c|c|c|c|c|c|c|c|}
\hline & \multicolumn{4}{|l|}{ Aggressive MS } & \multicolumn{4}{|c|}{ Comparator cohorts (non-aggressive MS) } \\
\hline & $\begin{array}{l}\text { AMS1 } \\
\mathrm{n} / \mathrm{N}=235 / 4285 \text { (5.5\%) }\end{array}$ & $\begin{array}{l}\text { AMS2 } \\
\mathrm{n} / \mathrm{N}=388 / 2762(14.0 \%)\end{array}$ & $\begin{array}{l}\text { AMS3 } \\
n / N=195 / 4918(4.0 \%)\end{array}$ & $\begin{array}{c}\text { Combined AMS1 and } 2 \\
\mathrm{n} / \mathrm{N}=523 / 3659(14.3 \%)\end{array}$ & $\begin{array}{l}C 1 \\
n=4050\end{array}$ & $\begin{array}{l}C 2 \\
n=2374\end{array}$ & $\begin{array}{l}\text { C3 } \\
n=4723\end{array}$ & $\begin{array}{l}\text { Combined non-AMS } \\
\text { (neither AMS1 nor AMS2) } \\
n=3136\end{array}$ \\
\hline \multicolumn{9}{|l|}{ Sex: $n(\%)$} \\
\hline Males & $95(40.4)$ & $135(34.8)$ & $76(39.0)$ & $192(36.7)$ & $1085(26.8)$ & $621(26.2)$ & $1210(25.6)$ & $857(27.3)$ \\
\hline Females & $140(59.6)$ & $253(65.2)$ & $119(61.0)$ & $331(63.3)$ & $2965(73.2)$ & $1753(73.8)$ & $3513(74.4)$ & $2279(72.7)$ \\
\hline Unadjusted $p$ valuet & $<0.0001 \ddagger$ & $<0.0001 \S$ & $<0.00019$ & $<0.0001 \mathrm{t \dagger}^{\dagger}$ & & & & \\
\hline Adjusted $p$ value & $<0.0001^{*}$ & $<0.0001^{*}$ & $<0.0001^{* *}$ & $<0.0001^{*}$ & & & & \\
\hline \multicolumn{9}{|l|}{ Disease course } \\
\hline Primary progressive MS & $60(25.5)$ & $28(7.2)$ & - & $73(14.0)$ & $277(6.8)$ & $93(3.9)$ & - & $254(8.1)$ \\
\hline Relapsing-onset MS & $175(74.5)$ & $360(92.8)$ & $195(100)$ & $450(86.0)$ & $3773(93.2)$ & $2281(96.1)$ & $4723(100)$ & $2882(91.9)$ \\
\hline Unadjusted $p$ valuet & $<0.0001 \ddagger$ & $<0.0001 \S$ & - & $<0.0001 \mathrm{t \dagger}$ & & & & \\
\hline Adjusted $p$ value & $<0.0001^{*}$ & $<0.0001^{*}$ & - & $<0.0001^{*}$ & & & & \\
\hline \multicolumn{9}{|c|}{ Age at symptom onset (years) } \\
\hline Mean $\pm S D$ & $39.8(11.51)$ & $25.6(4.68)$ & $38.1(10.67)$ & $31.3(11.23)$ & $32.6(8.99)$ & $30.9(5.8)$ & $31.9(8.65)$ & $34.7(8.91)$ \\
\hline Range & $19.1-71.5$ & $18.0-37.3$ & $18.0-68.5$ & $18.0-71.5$ & $18.0-73.1$ & $18.1-40.0$ & $18.0-75.2$ & $18.1-73.1$ \\
\hline Unadjusted $p$ value $\ddagger \ddagger$ & $0.0001 \ddagger$ & $<0.0001 \S$ & 0.00019 & $<0.0001+\dagger$ & & & & \\
\hline Adjusted $p$ value & $<0.0001^{*}$ & $<0.0001^{*}$ & $<0.0001^{*}$ & $<0.0001^{*}$ & & & & \\
\hline \multicolumn{9}{|c|}{ Patients exposed to a DMD (at anytime) } \\
\hline $\mathrm{n}(\%)$ & $98(41.7)$ & $148(38.1)$ & $45(23.1)$ & & $1640(40.5)$ & $931(39.2)$ & $1936(41.0)$ & \\
\hline 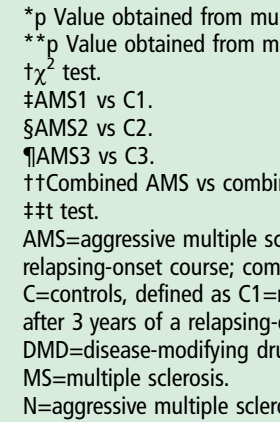 & $\begin{array}{l}\text { ariable logistic regression ana } \\
\text { ivariable logistic regression ar } \\
\text { non-AMS. } \\
\text { osis, defined as AMS1=Expan } \\
\text { ed AMS=AMS1 and AMS2. } \\
\text { reached EDSS } 6 \text { or greater w } \\
\text { et course; combined non-AM } \\
+ \text { +corresponding controls. }\end{array}$ & $\begin{array}{l}\text { Disability Status Scale (EDSS) } \\
5 \text { years from the onset of sy } \\
\text { either AMS1 nor AMS2, that }\end{array}$ & $\begin{array}{l}\text { or greater reached within } 5 \text { ye } \\
\text { toms; } C 2=\text { not reached EDSS } 6 \\
\text { not reached EDSS } 6 \text { or greater }\end{array}$ & $\begin{array}{l}\text { AMS2=EDSS } 6 \text { or greater rea } \\
\text { greater by age } 40 \text { years with } t \\
\text { thin } 5 \text { years from the onset of }\end{array}$ & $\begin{array}{l}d \text { by age } 40 \text { year } \\
\text { onset of sympto } \\
\text { aptoms or by age }\end{array}$ & $\begin{array}{l}\text { AMS3=seconda } \\
\text { between } 18 \text { an } \\
\text { years (both cr }\end{array}$ & $\begin{array}{l}\text { rogressive MS r } \\
\text { years; } C 3=\text { not } \\
\text { a had to be fulf }\end{array}$ & $\begin{array}{l}\text { ed within } 3 \text { years of a } \\
\text { ched secondary progressive MS } \\
\text { d). }\end{array}$ \\
\hline
\end{tabular}




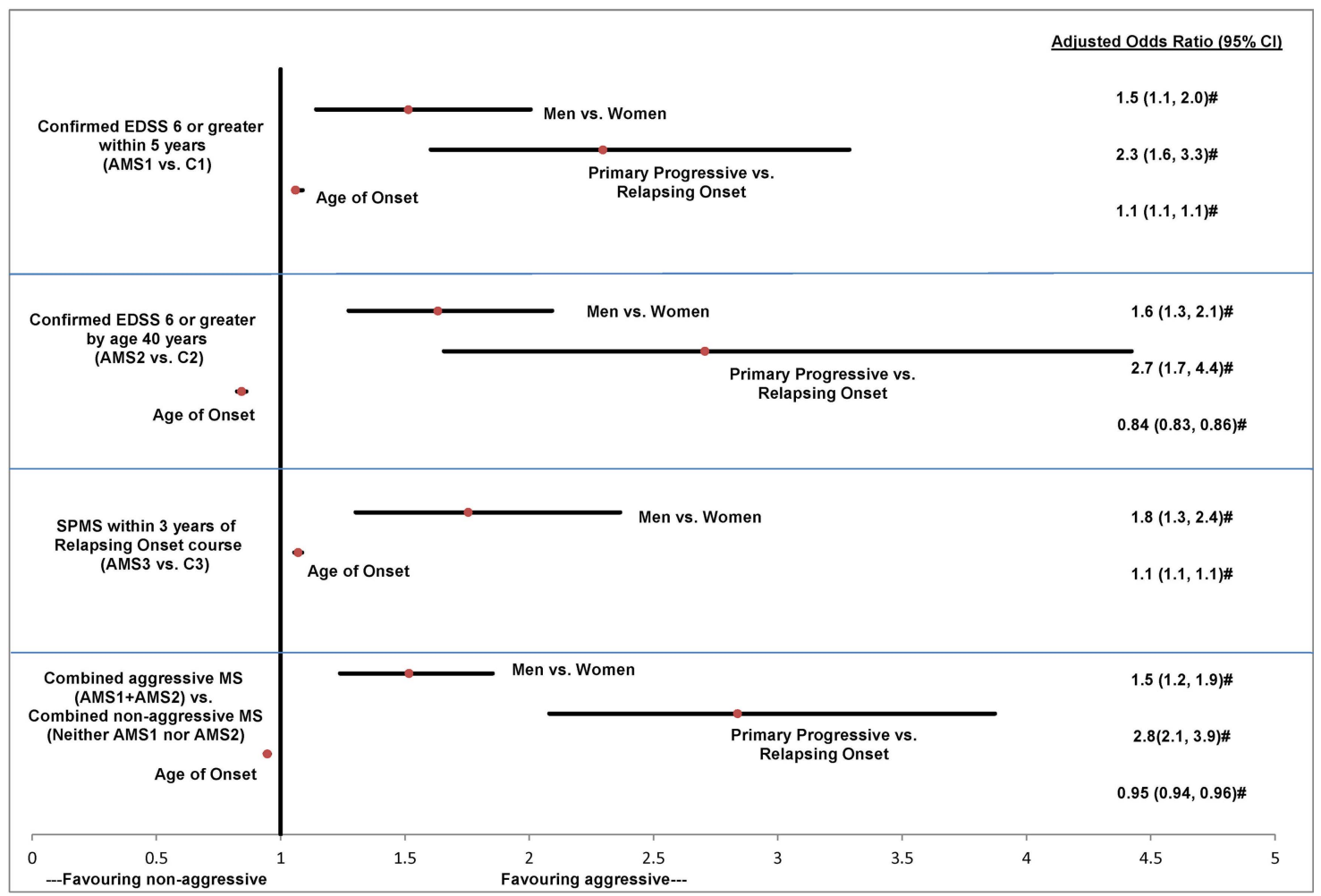

Figure 1 Multivariable logistic regression analysis of patients' characteristics associated with aggressive multiple sclerosis. Reference categorywomen, relapsing-onset MS; AMS, aggressive multiple sclerosis; EDSS, Expanded Disability Status Scale; SPMS, secondary progressive multiple sclerosis; \# significant $\mathrm{p}<0.0001$.

considered as they first came to clinic beyond 40 years of age and already had an EDSS score of 6 or greater at their first clinic visit. When compared to the source population, they were more likely to be male $(257 / 786,32.7 \%$ vs $1646 / 5891,27.9 \%$, $\mathrm{p}=0.003)$, with an older onset age $(36.8 \pm 11.0$ vs 33.4 \pm 9.6 years, $\mathrm{p}<0.0001)$ and have PPMS $(227 / 786,28.9 \%$ vs $589 / 5891,10.0 \%, \mathrm{p}<0.0001)$.

\section{AMS criterion (AMS1) -EDSS 6 or greater within 5 years}

A total of 235 patients fulfilled this criterion and 4050 formed the corresponding non-aggressive comparator cohort (C1) - that is, those who had not reached EDSS 6 or greater within 5 years from the onset of MS symptoms. Therefore the aggressive cohort constituted $5.5 \%$ of the 4285 eligible patients (AMS1 $+\mathrm{C} 1)$. Patients with AMS were more likely to be male $(p<0.0001)$, older at MS onset $(p<0.0001)$ and have a PP disease course $(p<0.0001)$, compared to those without AMS (C1). The direction of findings was similar both before and after adjusting for other variables (see table 2 and figure 1).

\section{AMS criterion (AMS2) -EDSS 6 or greater by the age of 40 years}

A total of 388 patients fulfilled this criterion and 2374 formed the corresponding non-aggressive comparator cohort (C2)that is, those who had not reached EDSS 6 or greater by age 40 years with the onset of MS symptoms between 18 and 40 years of age. Therefore the aggressive cohort constituted $14.0 \%$ of the total 2762 patients considered here (AMS2+C2). Compared to the control cohort (C2), those with AMS were more likely to be male, have PPMS and have a younger mean onset age (both before and after adjusting for other variables, $\mathrm{p}<0.0001$ ) (see table 2 and figure 1 ).
AMS criterion (AMS3)-SPMS within 3 years of a RO course A total of 195 patients fulfilled this criterion and 4723 formed the corresponding non-aggressive comparator cohort (C3) that is, those who had not reached SPMS after 3 years of a RO course. Therefore the aggressive cohort constituted $4.0 \%$ of the total 4918 (AMS3 + C3) patients considered here. Patients with AMS were more likely to be male $(p=0.0001)$ and older at MS onset $(p=0.0001)$ when compared to those without AMS (C3) (both before and after adjusting for other variables; see table 2 and figure 1).

\section{Combined AMS criteria (AMS 1 and 2)}

A total of 523 unique patients satisfied at least one of the criteria (AMS 1 or AMS 2) for AMS and 3136 unique patients who satisfied neither of the criteria and had sufficient follow-up formed the combined non-aggressive comparator cohort. Therefore the combined AMS cohort constituted 14.3\% of the total 3659 eligible patients. Patients in the combined AMS cohort were more likely to be male $(\mathrm{p}<0.0001)$, younger at the onset of MS symptoms $(p<0.0001)$ and have a PP disease course $(p<0.0001)$ when compared to those without AMS (combined non-AMS). The direction of findings was similar both before and after adjusting for other variables (see table 2 and figure 1).

\section{Use of DMDs}

Both the aggressive and comparator cohorts for the first two criteria included similar proportions of patients receiving a DMD at any point during follow-up (AMS1-41.7\%, C1-40.5\%, AMS2-38.1\% and C2-39.2\%). However for AMS3, 23.1\% of AMS patients were ever exposed to a DMD compared to $41.0 \%$ in the corresponding non-AMS cohort (C3). 


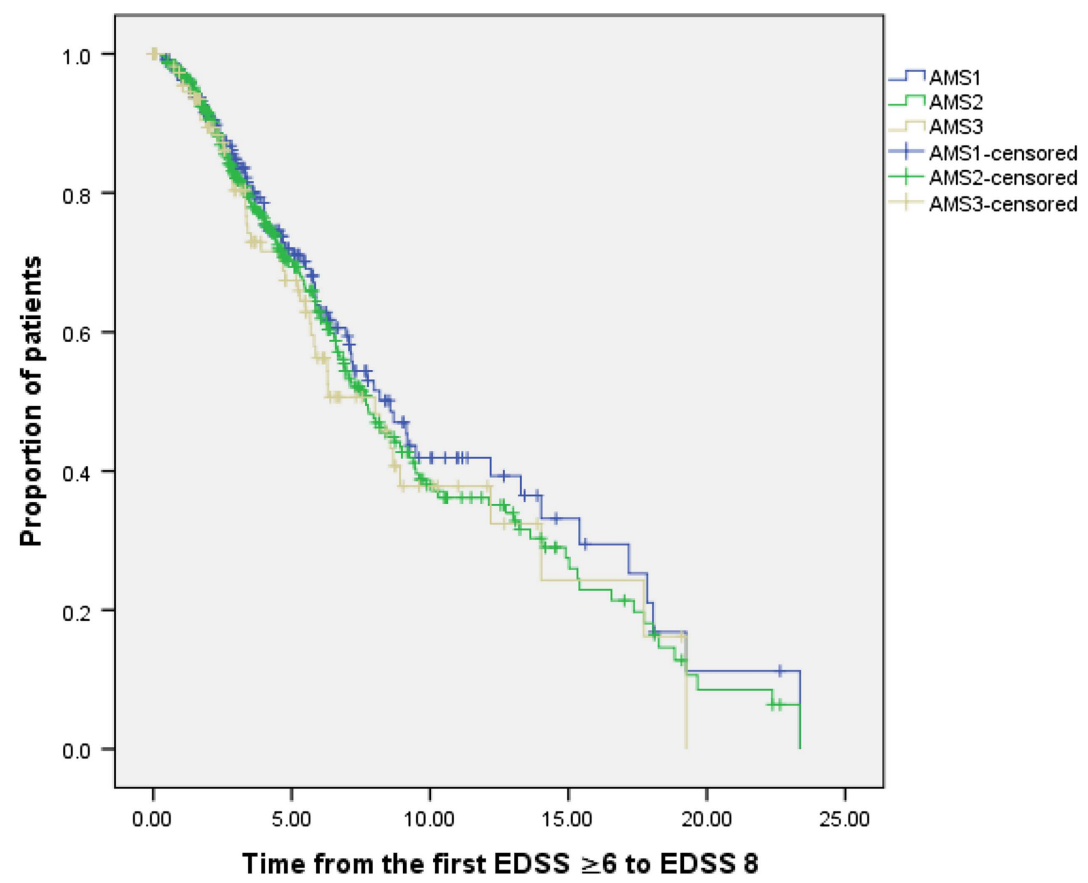

Median times (yrs) and patients at risk of progressing to EDSS 8 from the first EDSS score of $\geq 6$ at selected time points (yrs):

\begin{tabular}{|c|c|c|c|c|c|c|}
\hline Aggressive MS & Median Time (95\% Cl) & $\mathbf{0}$ & $\mathbf{5}$ & $\mathbf{1 0}$ & $\mathbf{1 5}$ & Censored patients \\
\hline AMS1 & $8.6(6.9-10.2)$ & 235 & 79 & 23 & 9 & $157(66.8 \%)$ \\
\hline AMS2 & $7.7(6.6-8.7)$ & 388 & 150 & 44 & 18 & $225(58.0 \%)$ \\
\hline AMS3 & $8.0(5.5-10.5)$ & 145 & 47 & 11 & 3 & $97(66.9 \%)$ \\
\hline
\end{tabular}

Figure 2 Kaplan-Meier survival curves of time to EDSS 8 from the first EDSS score of $\geq 6$ in patients with aggressive MS.

\section{Sensitivity analysis}

When extending the cut-off from 5 to 8 years for the criterion for AMS1, 477/3724 (12.8\%) were considered as having AMS. As before, those with AMS were more likely to be male (176/ $477,36.9 \%$ vs $852 / 3247,26.2 \%, \mathrm{p}<0.0001)$, older at MS onset (mean: $38.7 \pm 11.22$ vs $31.7 \pm 8.59$ years, $\mathrm{p}<0.0001$ ) and present with PPMS $(114 / 477,23.9 \%$ vs $205 / 3247,6.3 \%$, $\mathrm{p}<0.0001)$.

\section{Time to EDSS 8}

Median time to EDSS 8 from the first EDSS score of $\geq 6$ was similar across the three groups of patients with AMS (7.7, 8.0 and 8.6 years for AMS1, AMS2 and AMS3 cohorts, respectively; see figure 2).

\section{DISCUSSION}

We report on the occurrence and characteristics of patients with AMS in British Columbia, Canada. By exploring different individual definitions, we identified $4-14 \%$ of our patient population who could be considered as having AMS. We were able to find just one other study explicitly investigating AMS; this clinic-based study found $12.1 \%(n=59)$ of their cohort to have a 'malignant' status. ${ }^{12}$

We identified specific patient characteristics associated with the presence of AMS. Generally, men, those older at symptom onset and presenting with PPMS had higher odds of having AMS. These characteristics have typically been associated with a poorer outcome in previous natural history studies, albeit using different methodology and outcomes. ${ }^{27-31}$ However, it is of interest to note that despite these odds, around three out of every five patients identified as having AMS were women and the majority had RO MS (typical of MS in general). Additionally by virtue of the 'age at disability' selection criteria for AMS2, these patients were younger at symptom onset.

There has been relatively little focus on creating a specific definition for AMS. In contrast, over 10 definitions for the other extreme disease presentation-benign MS-exist. ${ }^{32-34}$ The absence of an accepted definition for AMS likely explains the dearth of studies explicitly describing this extreme disease presentation. Aside from Lublin and Reingold's descriptive definition of malignant $\mathrm{MS},{ }^{13}$ few have explored possible quantitative definitions. An early attempt in the 1970s to define 
'malignant' MS employed a disability grading scale no longer used in MS. ${ }^{35}$ Two other studies have selected 'malignant' patients based on a definition of EDSS of 6 or greater within 5 years of disease onset, ${ }^{12}{ }^{36}$ although only one did so with the aim of describing the epidemiology of this cohort. ${ }^{12}$

We have expanded on this definition by exploring two different EDSS-based criteria, incorporating both disease duration from onset and age, as well as including rapid deterioration from RO MS to SPMS. Both age and onset of SPMS are being increasingly recognised as essential to describe the evolution of disease in MS. ${ }^{25-28} 313738$ Also, by considering age, the impact and heavy disease burden of MS on relatively young adults was highlighted-we found that one in seven of MS patients who had the onset of symptoms before age 40 were unable to walk without a cane by age 40 (ie, had reached EDSS 6). Although these patients had a relatively young onset age and longer disease duration (by virtue of the selection criteria), such that they might not fulfil our 'classic' perception of AMS, we think they provide an important perspective with respect to the impact of MS on young adults. This level of disability has economic implications both at the individual level and for society as a whole. ${ }^{39} 40$

In addition, 1 in 25 RO patients progressed rapidly (within 3 years) to a secondary progressive course. Prompt identification of these patients could have important therapeutic implications, especially if a drug or other intervention were to become available that could significantly delay the onset of SPMS. We were unable to find another study using SPMS to define AMS.

Overall our study suggests that each of the three different definitions identifies a specific, important and informative subpopulation of AMS patients such that there may not be one single criterion 'superior' to the others.

Other important features of our definitions included the use of confirmed disability attainment within well-defined timelines, preventing misclassification, and allowing for the possibility of replication in other MS populations. We also evaluated and compared disease progression across the three groups, using another significant milestone, that is, time to wheelchair dependency (measured as EDSS 8) from the first EDSS score of $\geq 6$. Findings were similar across the three different criteria of AMS. This indicates that no one criterion was superior in terms of predicting future disability progression.

DMD exposure was similar among the different groups except for AMS3 where a much lower proportion of patients were ever exposed to a DMD. This may be because these patients by definition spent a relatively short period of time in the RR phase when the DMDs are considered most effective. Once the progressive phase begins, the therapeutic options are more limited.

Our study has additional clinical implications. First, many of the treatments for AMS are experimental, including autologous haematopoietic stem cell therapy. Our findings could help in the design of clinical trials for new therapeutics by providing explicit criteria for AMS, along with an estimate as to how many patients might be expected to present with this disease course. This type of information is vital for robust clinical trial design, including the determination of sample size or study power. Second, it is likely that patients with AMS are those most likely in urgent need of rehabilitation and palliative care services. Our study provides healthcare planners with an estimate of the prevalence of this type of MS disease course and the demographics of those affected. Lastly, by providing the much needed quantitative definitions for AMS, our study will possibly facilitate future studies investigating causation, susceptibility, expression or therapeutic interventions in this cohort of patients.
Strengths of our study include the population-based nature of the BCMS database, with an estimated $80 \%$ of the British Columbia MS population captured. Also, the patient follow-up in our study spans over 30 years and represents a significant natural history cohort.

Our study had some limitations. We had no information on the estimated $20 \%$ of patients not attending a BCMS clinic and thus not captured in the database. It is possible that patients with AMS lie in this 20\%, particularly if a very rapid disease progression results in severe disability and perhaps institutionalisation even before patients gain access to an MS clinic. By definition, it is likely that not all potentially eligible patients had a chance of being selected for this study-for example, those with more than 5 years of disease duration at their first clinic visit could not be considered in AMS1; however expanding this window in a sensitivity analysis resulted in largely similar findings. Also, a higher proportion of those excluded were older and had PPMS. It is possible that some of these patients would have been eligible; however how their inclusion might have affected findings is difficult to predict. Finally, we were unable to examine other potential important outcomes such as cognition, quality of life, employment or neuroimaging data, which would be useful to include in future studies.

In conclusion, using a combination of definitions we have identified from 1 in 25 up to 1 in 7 MS patients in British Columbia, Canada, as having AMS. Replication of findings in other longitudinal, largely natural history data sets would be of value. In addition, we hope that the data and findings presented stimulate further discussions and prompt the much needed creation of an internationally accepted consensus definition for AMS.

Acknowledgements We gratefully acknowledge the BC MS Clinic neurologists who contributed to the study through patient examination and data collection (current members listed here by primary clinic): UBC MS Clinic: A Traboulsee, MD, FRCPC (UBC Hospital MS Clinic Director and Acting Head of the UBC MS Programs); A-L Sayao, MD, FRCPC (Clinical Director of the BCMS Database); V Devonshire, MD, FRCPC; S Hashimoto, MD, FRCPC (UBC and Victoria MS Clinics); $J$ Hooge, MD, FRCPC (UBC and Prince George MS Clinic); L Kastrukoff, MD, FRCPC (UBC and Prince George MS Clinic); J Oger, MD, FRCPC. Kelowna MS Clinic: D Adams, MD, FRCPC; D Craig, MD, FRCPC; S Meckling, MD, FRCPC. Prince George MS Clinic: L Daly, MD, FRCPC. Victoria MS Clinic: 0 Hrebicek, MD, FRCPC; D Parton, MD, FRCPC; K Atwell-Pope, MD, FRCPC. The views expressed in this paper do not necessarily reflect the views of each individual acknowledged. We thank $T$ Duggan for his help in data coding.

Contributors SM: Study design, analysis and interpretation of data, drafting/ revising the manuscript for content, including medical writing for content, statistical analysis, obtaining funding. AS: Revising the manuscript for content, including medical writing for content, interpretation of data. YZ: Revising the manuscript for content, including medical writing for content, statistical analysis, interpretation of data. JO: Revising the manuscript for content, including medical writing for content, interpretation of data, administrative, technical, material support. AT: Revising the manuscript for content, including medical writing for content, interpretation of data. MF: Revising the manuscript for content, including medical writing for content, interpretation of data. HT: Study concept or design, interpretation of data, drafting/ revising the manuscript for content, including medical writing for content, acquisition of data, study supervision and coordination, obtaining funding, interpretation of data, administrative, technical, material support.

Funding Work carried out by the McDonald Fellowship (salary award) recipient from the Multiple Sclerosis International Federation.

Competing interests The British Columbia Multiple Sclerosis database has been funded via various grants over the years, including Canadian Institutes for Health Research (PI: HT), MS Society of Canada (PI: HT), National MS Society (PI: HT), the UBC MS/MRI Research Group and unrestricted grants from Dr Donald Paty. Suresh Menon is a recipient of the McDonald Fellowship from the Multiple Sclerosis International Federation. He has received travel awards/scholarship to present at conferences from the Consortium of MS Centres, Western Pacific endMS Regional Research and Training Centre and European Committee for the Treatment and Research in Multiple Sclerosis. Afsaneh Shirani is funded through a postdoctoral fellowship from the Multiple Sclerosis Society of Canada, and grants from the 
Canadian Institutes of Health Research (MOP-93646; PI: HT) and the National Multiple Sclerosis Society (RG 4202-A-2; PI: HT). She has received travel grants to present at and attend conferences from the endMS Research and Training Network (2010, 2011), the European Committee for Treatment and Research in Multiple Sclerosis $(2010,2011)$ and the Consortium of Multiple Sclerosis Centres (2012). Yinshan Zhao receives research funding from the National Multiple Sclerosis Society, the Canadian Institutes for Health Research and the Multiple Sclerosis Society of Canada. Joel Oger has received over the past 5 years speaker honoraria, consulting fees, travel grants and/or research grants and/or educational grants from Bayer, Biogen Idec, Genentech, Novartis, Serono, Shering, Talecris and Teva-neurosciences. He also receives fees for services from Bayer, Novartis and Biogen Idec to serve on advisory committees. Anthony Traboulsee received honorarium for membership on clinical trial steering committee for Roche and data safety monitoring board for Merck Serono. He received honorarium for presentations from EMD Serono, Biogen, Bayer and Sanofi Genzyme. Mark S Freedman-Receipt of research or educational grants: BayerHealthcare, Genzyme. Receipt of honoraria or consultation fees: Actelion, BayerHealthcare, Biogen Idec, Celgene, EMD Canada, Glycominds, Novartis, Sanofi-Aventis, Teva Canada Innovation. Member of a company advisory board, board of directors or other similar group: Actelion, BayerHealthcare, Biogen Idec, Celgene, Glycominds, Merck Serono, Novartis, Sanofi-Aventis. Participation in a company sponsored speaker's bureau: None. Helen Tremlett is funded by the Multiple Sclerosis Society of Canada (Don Paty Career Development Award) and Michael Smith Foundation for Health Research and is the Canada Research Chair for Neuroepidemiology and Multiple Sclerosis. She has received research support from the US National Multiple Sclerosis Society, CIHR and UK MS Trust; speaker honoraria and/or travel expenses to attend conferences from the Consortium of MS Centres, US National MS Society, the University of British Columbia Multiple Sclerosis Research Program, Bayer Pharmaceutical (speaker, 2010, honoraria declined), Teva Pharmaceuticals (speaker 2011), ECTRIMS (2011), UK MS Trust (2011), the Chesapeake Health Education Program, US Veterans Affairs (2012, honorarium declined) and Novartis Canada (2012). Unless otherwise stated, all speaker honoraria are either donated to an MS charity or to an unrestricted grant for use by her research group.

Ethics approval The study was approved by the Clinical Research Ethics Board at the University of British Columbia which includes informed patient consent (study number: H11-01677).

Provenance and peer review Not commissioned; externally peer reviewed.

\section{REFERENCES}

1 Compston A, Coles A. Multiple sclerosis. Lancet 2002;359:1221-31.

2 Capobianco M, Motuzova Y, Frau J, et al. Natalizumab in aggressive multiple sclerosis after haematopoietic stem cell transplantation. Neurol Sci 2012;33:863-7.

3 Fassas A, Kimiskidis VK, Sakellari I, et al. Long-term results of stem cell transplantation for MS: a single-center experience. Neurology 2011;76:1066-70.

4 Havrdova E. Aggressive multiple sclerosis-is there a role for stem cell transplantation? J Neurol 2005;252(Suppl 3):iii34-37.

5 Hirst $\mathrm{CL}$, Pace A, Pickersgill TP, et al. Campath 1-H treatment in patients with aggressive relapsing remitting multiple sclerosis. J Neurol 2008;255:231-8.

6 Le Page $E$, Leray $E$, Taurin $G$, et al. Mitoxantrone as induction treatment in aggressive relapsing remitting multiple sclerosis: treatment response factors in a 5 year follow-up observational study of 100 consecutive patients. J Neurol Neurosurg Psychiatry 2008;79:52-6.

7 Krishnan C, Kaplin Al, Brodsky RA, et al. Reduction of disease activity and disability with high-dose cyclophosphamide in patients with aggressive multiple sclerosis Arch Neurol 2008;65:1044-51.

8 Ostberg A, Pittas F, Taylor B. Use of low-dose mitozantrone to treat aggressive multiple sclerosis: a single-centre open-label study using patient self-assessment and clinical measures of multiple sclerosis status. Intern Med J 2005:35:382-7.

9 Herbert J. Defining "malignant multiple sclerosis". P703. Abstract from the 23rd congress of the European Committee for Treatment and Research in Multiple Sclerosis and the 12th annual conference of Rehabilitation in Multiple Sclerosis. October 11-14, 2007. Prague, Czech Republic. Mult Scler 2007;13(Suppl 2):S212.

10 Kimiskidis V, Sakellari I, Tsimourtou V, et al. Autologous stem-cell transplantation in malignant multiple sclerosis: a case with a favorable long-term outcome. Mult Scler 2008:14:278-83.

11 Mancardi GL, Murialdo A, Rossi P, et al. Autologous stem cell transplantation as rescue therapy in malignant forms of multiple sclerosis. Mult Scler 2005;11:367-71.
12 Gholipour T, Healy B, Baruch NF, et al. Demographic and clinical characteristics of malignant multiple sclerosis. Neurology 2011;76:1996-2001.

13 Lublin FD, Reingold SC. Defining the clinical course of multiple sclerosis: results of an international survey. National Multiple Sclerosis Society (USA) advisory committee on clinical trials of new agents in multiple aclerosis. Neurology 1996;46:907-11.

14 Capello E, Mancardi GL. Marburg type and Balo's concentric sclerosis: rare and acute variants of multiple sclerosis. Neurol Sci 2004;25(Suppl 4):S361-3.

15 Elenein RG, Sharer LR, Cook SD, et al. A second case of Marburg's variant of multiple sclerosis with vasculitis and extensive demyelination. Mult Scler 2011:17:1531-8

16 Gonzalez Sanchez JJ, Nora JE, de Notaris M, et al. A case of malignant monophasic multiple sclerosis (Marburg's disease type) successfully treated with decompressive hemicraniectomy. J Neurol Neurosurg Psychiatry 2010;81:1056-7.

17 Mendez MF, Pogacar S. Malignant monophasic multiple sclerosis or "Marburg's disease". Neurology 1988;38:1153-5.

18 Nozaki K, Abou-Fayssal N. High dose cyclophosphamide treatment in Marburg variant multiple sclerosis: a case report. J Neurol Sci 2010;296:121-3.

19 Rohani M, Ghourchian S. Fulminant multiple sclerosis (MS). Neurol Sci 2011;32:953-7.

20 Talab R, Kundrata Z. Marburg variant multiple sclerosis-a case report. Neuro Endocrinol Lett 2011:32:415-20.

21 Sweeney VP, Sadovnick AD, Brandejs V. Prevalence of multiple sclerosis in British Columbia. Can J Neurol Sci 1986;13:47-51.

22 Sadovnick $A D$, Ebers $G C$, Wilson RW, et al. Life expectancy in patients attending multiple sclerosis clinics. Neurology 1992;42:991-4.

23 Poser CM, Paty DW, Scheinberg L, et al. New diagnostic criteria for multiple sclerosis: guidelines for research protocols. Ann Neurol 1983:13:227-31.

24 McDonald WI, Compston A, Edan G, et al. Recommended diagnostic criteria for multiple sclerosis: guidelines from the international panel on the diagnosis of multiple sclerosis. Ann Neurol 2001;50:121-7.

25 Tremlett H, Yinshan Z, Devonshire V. Natural history of secondary-progressive multiple sclerosis. Mult Scler 2008;14:314-24.

26 Koch $M$, Kingwell E, Rieckmann $P$, et al. The natural history of primary progressive multiple sclerosis. Neurology 2009;73:1996-2002.

27 Tremlett H, Zhao Y, Devonshire V, UBC Neurologists. Natural history comparisons of primary and secondary progressive multiple sclerosis reveals differences and similarities. J Neurol 2009;256:374-81.

28 Tremlett $\mathrm{H}$, Zhao $\mathrm{Y}$, Rieckmann $\mathrm{P}$, et al. New perspectives in the natural history of multiple sclerosis. Neurology 2010;74:2004-15.

29 Degenhardt A, Ramagopalan SV, Scalfari A, et al. Clinical prognostic factors in multiple sclerosis: a natural history review. Nat Rev Neurol 2009;5:672-82.

30 Confavreux C, Compston A, McDonald I, et al. The cause and course of multiple sclerosis. In: Compston A. McAlpine's multiple sclerosis. 4th edn. Philadelphia, PA: Churchill Livingstone Elsevier, 2005:69-284.

31 Tremlett H, Paty D, Devonshire V. Disability progression in MS is slower than previously reported. Neurology. 2006;66:172-7.

32 Sayao AL, Devonshire $\mathrm{V}$, Tremlett $\mathrm{H}$. Longitudinal follow-up of "benign" multiple sclerosis at 20 years. Neurology 2007;68:496-500.

33 Costelloe L, Thompson A, Walsh C, et al. Long-term clinical relevance of criteria for designating multiple sclerosis as benign after 10 years of disease. J Neurol Neurosurg Psychiatry 2008;79:1245-8.

34 Correale J, Peirano I, Romano L. Benign multiple sclerosis: a new definition of this entity is needed. Mult Scler 2012;18:210-18.

35 Poser S, Wikstrom J, Bauer HJ. Clinical data and the identification of special forms of multiple sclerosis in 1271 cases studied with a standardized documentation system. J Neurol Sci 1979:40:159-68.

36 DeLuca GC, Ramagopalan SV, Herrera BM, et al. An extremes of outcome strategy provides evidence that multiple sclerosis severity is determined by alleles at the HLA-DRB1 locus. Proc Natl Acad Sci USA 2007;104:20896-901.

37 Tremlett $H$, Paty D, Devonshire V. Disability progression in multiple sclerosis is slower than previously reported. Neurology 2006;66:172-7.

38 Scalfari $A$, Neuhaus $A$, Daumer $M$, et al. Age and disability accumulation in multiple sclerosis. Neurology 2011;77:1246-52.

39 Karampampa K, Gustavsson A, Miltenburger C, et al. Treatment experience, burden and unmet needs (TRIBUNE) in MS study: results from five European countries. Mult Scler 2012;18:7-15

40 Karampampa K, Gustavsson A, Miltenburger C, et al. Treatment experience, burden, and unmet needs (TRIBUNE) in multiple sclerosis: the costs and utilities of MS patients in Canada. J Popul Ther Clin Pharmacol 2012;19:e11-25. 